\title{
Investment in resilient food systems in the most vulnerable and fragile regions is critical
}

\author{
Reversing the alarming trend of rising food insecurity requires transformations towards just, sustainable and \\ healthy food systems with an explicit focus on the most vulnerable and fragile regions. \\ Cibele Queiroz, Albert V. Norström, Andrea Downing, Zuzana V. Harmáčková, Cedric De Coning, \\ Vanessa Adams, Mohamed Bakarr, Tobias Baedeker, Ange Chitate, Owen Gaffney, Line Gordon, \\ Étienne Hainzelin, David Howlett, Florian Krampe, Ana Maria Loboguerrero, Deon Nel, Constance Okollet, \\ Maya Rebermark, Johan Rockström, Mark Smith, Sylvie Wabbes-Candotti and Nathanial Matthews
}

G lobal food insecurity fell for decades, but it is steadily rising again ${ }^{1}$. A primary driver of this alarming trend is the double burden of climate shocks and violent conflict in areas that are already food insecure. The recent COVID-19 crisis is exacerbating this trajectory ${ }^{1}$.

Bending the curve of rising food insecurity while achieving global climate and sustainability targets (for example, the Sustainable Development Goals (SDGs)) and remaining within planetary boundaries will require a fundamental transformation of the global food system ${ }^{2}$. The need for transformative change is widely accepted, but how it will play out in vulnerable contexts is far less explored.

Transformations of food systems must explicitly address the challenges and meet the needs of the most vulnerable and fragile regions (Fig. 1). The reasons for this are twofold. First, the impacts of food insecurity are highest in these regions ${ }^{3,4}$. Exposure to climate shocks and violent conflict is high, most people depend on local food systems for their subsistence, and the capacity to adapt and transform in the face of change is eroded ${ }^{5}$. If the realities and needs of vulnerable and fragile regions are ignored, the social injustices and environmental pressures experienced by these communities will be aggravated and lead to further food insecurity, conflict, violence and displacement ${ }^{4}$. Second, many of the main carbon sinks and biodiversity hotspots of global importance are located in these regions, meaning that accomplishing global climate and biodiversity targets will depend on the governance of these natural ecosystems. This poses an extra burden on countries already facing severe challenges and often lacking the institutional capacity for ensuring long-term sustainability ${ }^{6-8}$.

In the following sections we propose three action points to advance a global food system transformation in ways that prioritize the realities and needs of vulnerable and fragile regions. Besides being context-specific, they highlight the need to move beyond siloed approaches (such as food relief or investments in productivity alone) and the importance of building diverse coalitions of actors across multiple sectors (government, business, civil society, local and indigenous communities, and academia). Importantly, they recognize that social-ecological resilience is a precondition for a sustainable and just food system transformation. The three proposed actions are linked to major intervention categories listed in Table 1 and were identified on the basis of our diverse collective experience and expertise working across the sciencepolicy interface, as well as recent scientific evidence. They should not be seen as an exhaustive list, or a final blueprint for action; instead, we hope that they stimulate further discussion.

\section{Halt agricultural land expansion but invest in food security}

Ensuring global long-term food security requires global climate and biodiversity targets to be met. Agricultural land expansion needs to be halted, while the sustainability and productivity of existing production systems must be increased and degraded lands restored.

In vulnerable and fragile contexts, this will require investments in integrated farm-livelihood approaches, together with systemic forms of sustainable intensification ${ }^{9}$. The application of on-site solutions such as integrated soil and water management systems, water harvesting practices, conservation tillage, and integrated watershed and landscape planning can help increase productivity, raise system diversity and reduce farmer costs while reducing negative externalities ${ }^{9}$. Smallholder farms need to be at the focus of such strategies, given their ability to generate high yields while promoting biodiversity at the farm and landscape scales ${ }^{10}$. Sustainable intensification can also be applied to animal production systems, for example through the use of agroforestry. Feeding animals with tree leaves can lead to higher meat and milk productivity ${ }^{11}$, reducing the amount of methane released per kilogram of food produced while contributing to carbon sequestration. Sustainable intensification of animal production can be particularly important in vulnerable and fragile regions, as animals are one of the main assets and sources of food security to households in rural communities. Although transformations towards more sustainable and climate-resilient food systems require a major shift to plant-based diets in most parts of the world, we need to take into account the context-specific differences in how these transitions should be made. Removing animal food sources from these regions would have major negative impacts on food security. Sustainable intensification of animal production can be an alternative way of achieving the double goals of food security and sustainability in some of these regions.

Halting agricultural land expansion in countries suffering from extreme food insecurity can result in short-term impacts and lost benefits ${ }^{8}$. It could be further complicated by substantial projected population growth over the next few decades in many of these regions. Furthermore, many food-insecure countries (which are often vulnerable or fragile; Fig. 1) host areas of high conservation value, such as biodiversity hotspots and large tracts of forest carbon sinks ${ }^{8}$. Although it is possible to combine the double goals of biodiversity and food security, this overlap might create further challenges to management and governance of these areas. It is therefore essential that land and water governance 
a
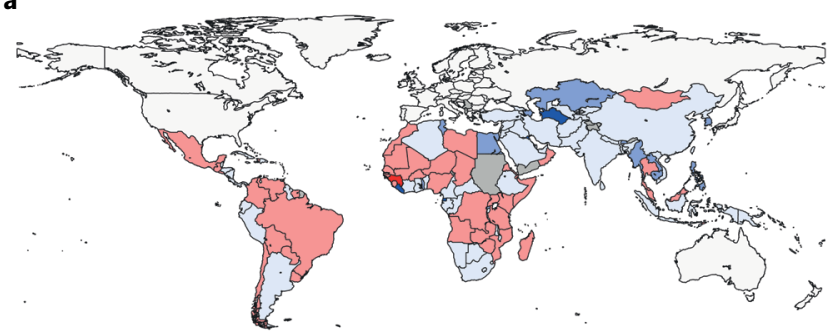

Vulnerability change (\%)

$\square$ No change

-60 to -40

-40 to -20

$\square-20$ to 0

0 to 20

20 to 30

b
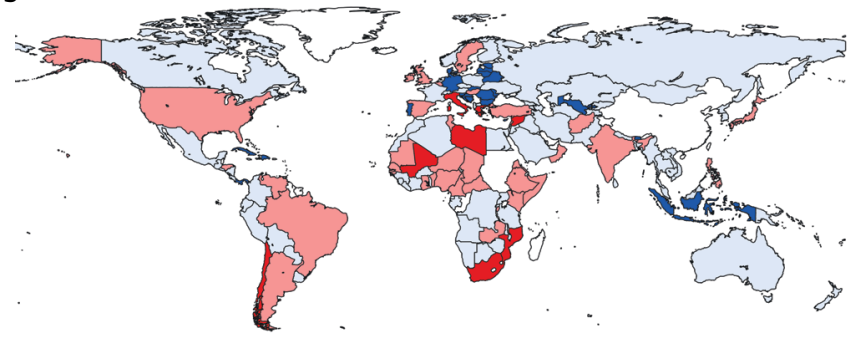

Fragility change 2006-2020 (\%)

$\square$ No change

$<-20$

-20 to 0

0 to 20

$>20$

c
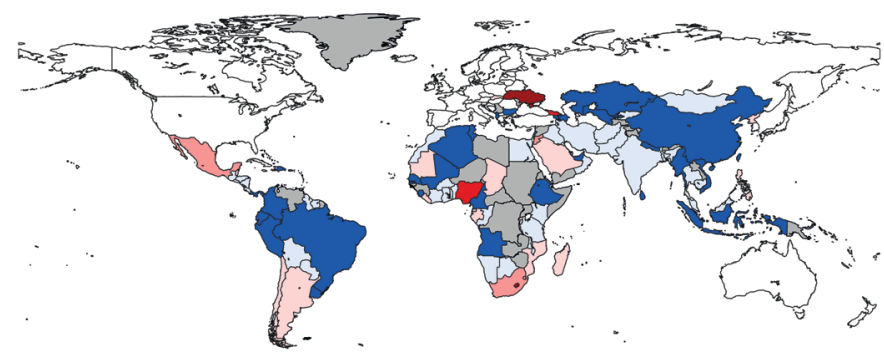

Change in nourishment prevalence 2006-2018 (\%)

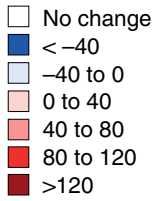

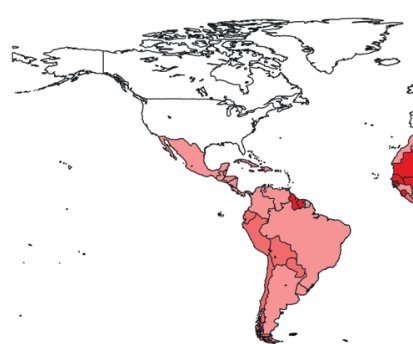

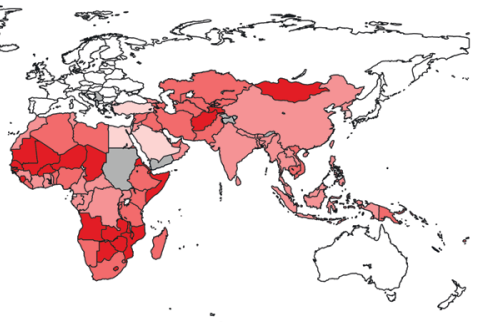

Vulnerability index 2020

$\square 0$ to 10

$\square 10$ to -20

20 to 30

30 to 40

40 to 50

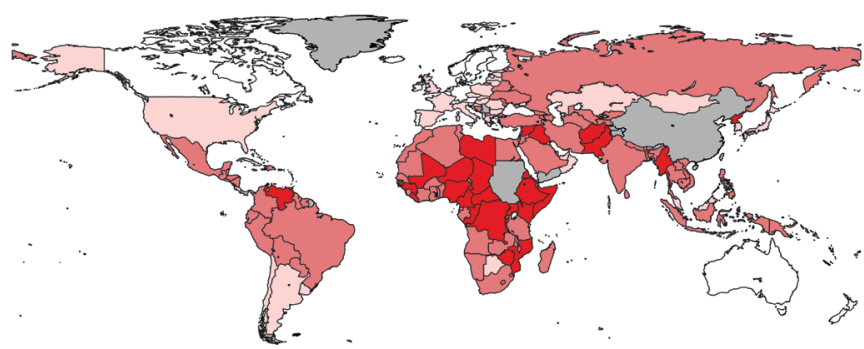

Fragility index 2020

$\square$ Sustainable

$\square$ Stable

Warning

Alert
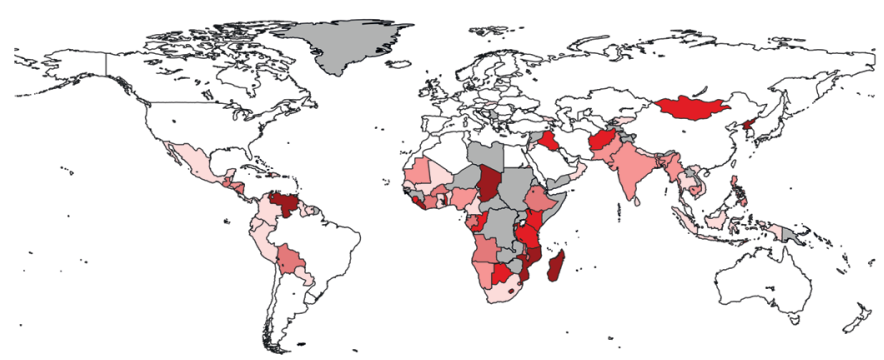

Undernourishment prevalence $2018(\%)$

$\square 0$ to 5

$\square$ to 10

$\square \quad 10$ to 15

$\square 15$ to 20

20 to 30

$>30$

Fig. 1 | Vulnerability, fragility and food insecurity around the world. a, Vulnerability as indicated by the UN Environment Programme's Economic and Environmental Vulnerability index ${ }^{48}$, here defined as a system's susceptibility to harm from exposure to environmental or socio-economic stresses and from the lack of adaptive capacity ${ }^{5,49}$. b. Fragility as indicated by the Fragile States Index ${ }^{50}$, here defined as the lack of elements necessary for a system to function effectively. Examples include weak, ineffective or unstable political institutions; the inability to exercise effective jurisdiction over the territory; legitimacy crises; contested citizenship; malfunctioning institutions of conflict management and resolution; pervasive corruption; poverty; and low levels of economic growth and development ${ }^{6}$. c, Food insecurity as indicated by the prevalence of undernourishment across the world ${ }^{51}$. Food security simultaneously depends on food availability, access and utilization, as well as the stability of these three dimensions over time. In vulnerable and fragile regions, exposure to disturbances is higher, while the capacity of individuals, communities and institutions to respond is eroded - ultimately leading to greater risk of food insecurity and associated impacts. The left column shows the percentage change in each indicator since 2006, and the right column shows the latest indicator value available. Country borders were retrieved from The World Bank Data Catalog ${ }^{52}$. 
Table 1 | Examples of evidence-based interventions across the proposed three action areas

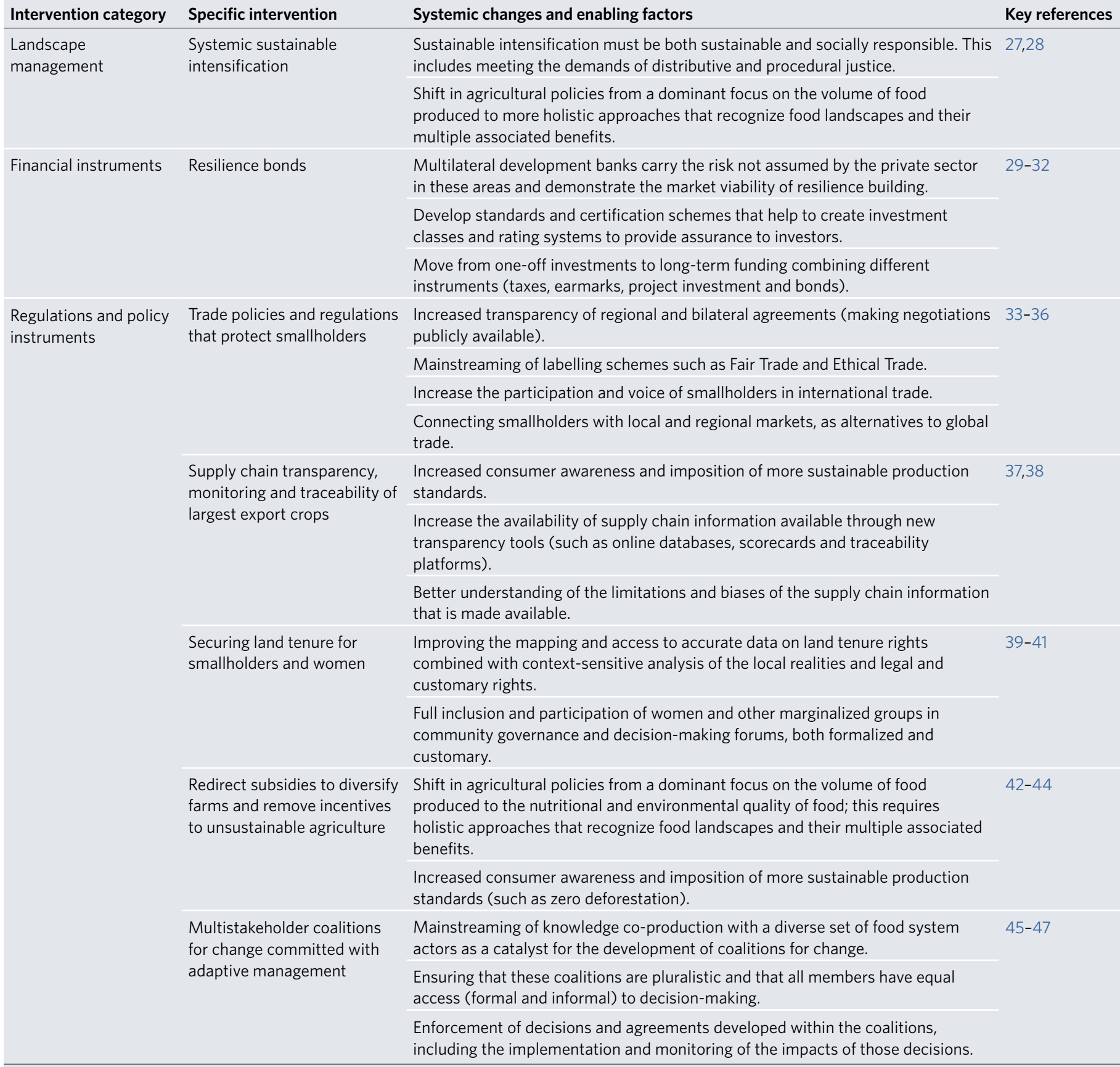

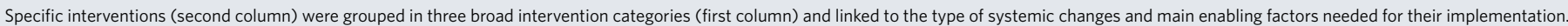
This list is not intended to be exhaustive or exclusive, but instead to provide additional detail on the multiple levels of action required.

accompany investments in sustainable intensification practices in ways that ensure distributed, equitable long-term local benefits that outweigh potentially foregone benefits of continued land expansion.

Fragile regions often lack the political and institutional capacity to effectively implement measures that halt land expansion, even when economic incentives are provided through external programmes ${ }^{6,7}$. Incentives targeting local and regional scales and other actors than national governments might be more effective for immediate action, especially when combined with measures for securing land tenure for small-scale farmers, women and indigenous communities. For instance, in many countries where forests are "a property of the state" ${ }^{\text {, governments }}$ allocate large forested areas to agribusiness and other large-scale actors, potentially perpetuating unsustainable agricultural practices and land expansion.

Ultimately, it is the root causes and global drivers of agricultural expansion that need to be confronted. Export crops such as soybean and palm oil produced for the European Union, United States and Chinese markets are a primary driver of agricultural expansion and deforestation across the 
tropics. Halting agricultural expansion and deforestation might be most effectively tackled by targeting the supply chains of a small set of export crops. An important role is played by urban population growth and large transnational corporations that link production systems globally through their subsidiaries. A growing number of tools and data sources such as Global Forest Watch (https://globalforestwatch. org/) and Trase (https://www.trase.earth/) can help companies reach higher levels of supply chain transparency, monitoring and traceability and reduce land expansion and degradation in their supply chains. Pressure from governments, finance ministries and consumers is essential to promote new norms and regulations. Advocacy and campaigns by grassroots movements, and other civil society organizations, will be important to promote awareness and help stimulate regulatory actions.

\section{Put resilient landscapes at the heart of transformation}

Vulnerable and fragile regions face high levels of environmental, socio-economic and political turbulence. This disrupts local and regional food systems, with negative impacts on food security. The effects of this turbulence can spread across sectors and geographic scales given the interconnectivity of the global food system ${ }^{12}$. Thus, increasing the resilience of food landscapes and seascapes in these regions is key to minimize detrimental impacts and ensure local and global food security.

A diversity of nutritious crops and animal foods (including blue foods such as fish, invertebrates and aquatic plants captured or cultured in freshwater and marine ecosystems), as well as farming practices and business models, builds resilience. It reduces the need for external inputs, builds soil ecosystem health and allows for a higher diversity of responses to shocks and disturbances ${ }^{13}$. Consequently, it enhances yields in the long run and contributes to more stable national food supplies - even in regions exposed to stress or under protracted crisis.

The challenge lies in creating both policy and business incentives for building resilience. Recent work has highlighted the potential of redirecting finance towards resilience and sustainability ${ }^{12,14}$. New innovations and investment in the bonds market, such as agricultural resilience bonds, can be used to create incentives for farmers, fishers and agribusiness to invest in resilience practices adapted to the local context, and buffer potential short-term costs or yield losses. The world's first dedicated climate-resilient bond was issued by the European Bank for Reconstruction and Development in 2019, and the possible application of resilience bonds in India's highly vulnerable agricultural sector is being explored by the World Resource Institute and Climate Bonds Initiative. Loan covenants (the specific conditions associated with credit lending) are another powerful tool with which banks can influence the behaviour of borrowing companies operating in food systems in vulnerable and fragile contexts, by denying access to clients that do not comply with resilience standards and principles ${ }^{15}$. The UN Food and Agriculture Organization (FAO) and World Health Organization (WHO) Food Standards Programme can also make amendments to the Codex Alimentarius (a collection of international food standards, guidelines and codes of practice) so that it includes standards of resilience, while securing the commitment of agribusiness to use the amended Codex.

Further incentives can be created by shifting agricultural policies away from a singular focus on yields and productivity to approaches that value and reward the diverse socio-economic, public health and environmental benefits of sustainable food landscapes. Emerging approaches, such as true cost accounting of food, are already being implemented at national and farm levels as a way to incentivize more sustainable food production practices ${ }^{16}$. Governments, intergovernmental and civil society organizations should redirect subsidies so that they support the diversification of farms, waste reduction and risk management. Subsidies need to be proportional to farmers' needs and vulnerabilities (those who need the most, get the most) and move beyond payments for farm area or simplistic 'yield per hectare' metrics that benefit large-scale actors. Payments for ecosystem services schemes can reward smallholder farmers for their contribution to generating multiple ecosystem services other than crop or livestock production. Although the effectiveness of such schemes is contested, insights from different case studies suggest that these have enhanced livelihood assets in several places ${ }^{17}$.

In fragile regions, obstacles to the implementation of resilience measures such as weak or unstable institutions or high corruption are an additional challenge. In these contexts, it can be more effective to provide direct support from external actors such as international non-governmental organizations or intergovernmental organizations to local actors and communities through incentives such as the ones described above.
Providing smallholder farmers with the means to monitor, predict and respond to social, political and environmental changes is essential for effective adaptive management of agricultural landscapes ${ }^{18}$. Investments in increased accessibility of new mobile technology that supports online financial services, access to up-to-date weather services and forecasts and to farmer-group instant communication platforms can support such practices. In fragile regions, such as Mali and Sudan, community groups and civil society organizations have helped create learning platforms through which communities use the experience from past conflicts to co-develop early warning systems for future conflict emergence ${ }^{19}$.

Adaptive management approaches for building diverse, resilient and nutritious food landscapes require long-term commitments of coalitions for change that include local actors, grassroots organizations, national and international non-governmental organizations, national governments, international financial institutions, multilateral funds - such as the Global Environment Facility and Green Climate Fund - and donor organizations. As part of coalitions for change, agribusinesses and multilateral organizations can step up to a role of 'keystone actors ${ }^{20}$ for inclusive food system stewardship towards resilience and sustainability. Owing to their disproportional impact on food systems (particularly in low-income countries) these keystone actors are well positioned to trigger large-scale positive food system transformations in these regions. For example, in 2020 the CEOs of ten dominant seafood companies committed to eliminate illegal, unregulated and unreported fishing from their operations by October 2021 (ref. ${ }^{21}$ ). Although the long-term outcome remains to be seen, this is a major step towards confronting unsustainable fisheries management and associated labour abuse that is of great concern in many vulnerable and fragile regions. Another positive example is the CDP Supply Chain programme, which assesses the climate, water and deforestation impacts of the supply chains of large corporate purchasers, and has grown to 154 major organizations with over 8,000 top-tier global suppliers engaged in the past decade ${ }^{22}$. These promising initiatives can help to make the business case for diverse, nutritious systems that underpin resilience across entire value chains, landscapes and seascapes. However, they also raise concerns associated with accountability, representation and the risk of perpetuating the power dynamics underpinning the deep-rooted inequalities 
in the global food system. It is therefore crucial to ensure that the proposed coalitions of change remain pluralistic, and that the interests of the most vulnerable are represented by grassroots movements, local governments and civil society organizations.

\section{Build conflict-resilient food systems}

While transformations to resilient, inclusive and sustainable food systems are a major leverage point for achieving global sustainable development ${ }^{2}$, conflict can be a considerable barrier. Conflict-affected areas are particularly vulnerable to shocks such as changes in food prices or trade disruptions, such as the ones originated by the COVID-19 crisis.

At present, two billion people live in countries where development outcomes are affected by fragility, conflict and violence $^{23}$. When an existing conflict situation is also affected by climate change it tends to aggravate violent conflict, inhibit peacebuilding and increase the human costs of war $^{24}$. For example, climate change can exacerbate the circular link between conflict and food insecurity ${ }^{4}$ with negative consequences for stability. We argue that resilient food systems are critical for building and maintaining stability in societies that are vulnerable to conflict.

Traditional humanitarian and food aid approaches in these fragile areas have been questioned. They can fail to effectively distribute food to the most vulnerable, and they can undermine capacity building and economic development by creating aid-dependent economies ${ }^{25}$. A recent systematic review found that humanitarian and food aid in conflict zones is on the aggregate more likely to exacerbate conflict dynamics than to dampen violence ${ }^{26}$. Moreover, when local food systems are vulnerable to environmental change, tensions between longer-term management and the immediate use of natural resources increase, potentially developing into conflicts that in turn undermine the communities' capacity to adapt to new environmental stresses ${ }^{4}$. This increased vulnerability also makes individuals in such communities more prone to be recruited to larger-scale armed conflicts ${ }^{24}$. The increased resilience of local food systems reduces those vulnerabilities and, by boosting local livelihoods, makes individuals less prone to be recruited to conflict. Finally, the collaborative and participatory process of building resilient food systems can strengthen collective action, and align the interests of broad coalitions of relevant actors in the food system.

In most fragile contexts, the lack of strong institutions requires alternative and comprehensive approaches to boost food system resilience that do not only rely on state-level actors or formal institutions, and that allow for a more extensive and inclusive identification of key actors and interventions ${ }^{24}$. Existing tools and emerging technology can support such processes.

Whole-system approaches that interlink investments across sectors are key to ensure the success of resilience building actions and initiatives and prevent relapses into conflict. Some positive examples exist, such as the Country Resilience and Fragility Assessment - a new tool created by the African Development Bank that assesses systemic resilience and fragility using seven key criteria: political inclusiveness, safety and security, justice, the economy, social cohesion, the regional contagion effect and climate change. Information on land tenure distribution can provide valuable support in land governance issues, including the resolution of conflicts related to forced displacements. Importantly, this information needs to be combined with context-sensitive analysis of the local realities, including common property resources use (where individual titling might not be appropriate) and inequalities in women's access to decision-making in the community and in land governance.

Investments in building stability from resilient food systems must apply conflict-sensitive approaches based on the understanding of the local on-site dynamics, the cross-scale dynamics of trade and international relations and the inequalities of land tenure and land rights, as well as the different vulnerabilities to environmental change.

\section{Final remarks}

With the UN Food Systems Summit approaching, there is a growing concern over ensuring that any approaches and solutions proposed contribute to both a sustainable and just transformation. But for this to be achieved, we need a policy agenda with a much stronger focus on the needs and challenges of the people living in vulnerable and fragile regions, as well as the recognition that it is only by addressing those challenges in an integrated socialecological way that we will be able to get to the heart of our global food system's problems. It is imperative that we take advantage of the momentum and the current focus on game-changing solutions promoted by the UN Food Systems Summit to adopt transformative food systems actions that move away from 'one size fits it all' solutions. Comprehensive and context-specific approaches such as the ones proposed here can help to guide such processes.

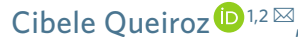

Albert V. Norström (D) 1,2,

Andrea Downing (iD) 2,3

Zuzana V. Harmáčková (D) 2,4

Cedric De Coning (D5, Vanessa Adams ${ }^{6}$,

Mohamed Bakarr ${ }^{7}$, Tobias Baedeker ${ }^{8}$,

Ange Chitate (D) ${ }^{9}$, Owen Gaffney ${ }^{10}$,

Line Gordon (D1), Étienne Hainzelin",

David Howlett ${ }^{1}$, Florian Krampe (D) 12 ,

Ana Maria Loboguerrero (DD) ${ }^{13}$, Deon $\mathrm{Ne}^{14}$,

Constance Okollet ${ }^{15}$, Maya Rebermark ${ }^{16}$,

Johan Rockström (D) 2,10

Mark Smith ${ }^{17}$, Sylvie Wabbes-Candotti ${ }^{18}$ and

Nathanial Matthews (D) 1

${ }^{1}$ Global Resilience Partnership, Stockholm, Sweden. ${ }^{2}$ Stockholm Resilience Centre, Stockholm, Sweden. ${ }^{3}$ Swedish Royal Academy of Sciences, Stockholm, Sweden. ${ }^{4}$ Global Change Research Institute of the Czech Academy of Sciences, Brno, Czechia. ${ }^{5}$ Norwegian Institute of International Affairs, Oslo, Norway. ${ }^{6}$ Alliance for a Green Revolution in Africa (AGRA), Nairobi, Kenya. ${ }^{7}$ Global Environment Facility (GEF), Washington, DC, USA. ${ }^{8}$ World Bank, Washington, DC, USA. ${ }^{9}$ African Risk Capacity Ltd, Johannesburg, South Africa. ${ }^{10}$ Potsdam Institute for Climate Impact Research (PIK), Potsdam, Germany. ${ }^{11}$ Cirad-Agricultural Research for Development, Paris, France. ${ }^{12}$ Stockholm International Peace Research Institute (SIPRI), Solna, Sweden. ${ }^{13}$ CGIAR Research Program on Climate Change, Agriculture and Food Security (CCAFS) and International Center for Tropical Agriculture, Cali, Colombia. ${ }^{14}$ WWF Netherlands, Zeist, the Netherlands. ${ }^{15}$ Osukuru Unites Women's Network (OWN), Osukuru, Uganda. ${ }^{16}$ Misum-Mistra Centre for Sustainable Markets, Stockholm School of Economics, Stockholm, Sweden. ${ }^{17}$ International Water Management Institute, Colombo, Sri Lanka. ${ }^{18}$ Food and Agriculture Organization of the United Nations, Rome, Italy.

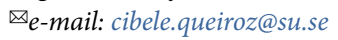

Published online: 18 August 2021 https://doi.org/10.1038/s43016-021-00345-2

References

1. Hunger and COVID-19 Snapshots (Hunger Monitoring Unit, WFP, accessed 10 April 2021); https://go.nature.com/37p2ilz

2. Willett, W. et al. Lancet 393, 447-492 (2019)

3. Berazneva, J. \& Lee, D. R. Food Policy 39, 28-39 (2013).

4. Brinkman, H.-J. \& Hendrix, C. S. Food Insecurity and Conflict: Applying the WDR Framework World Development Report 2011 Background Papers (World Bank, 2011).

5. Adger, W. N. Glob. Environ. Change 16, 268-281 (2006).

6. Osaghae, E. E. Dev. Practice 17, 691-699 (2007).

7. Karsenty, A. \& Ongolo, S. For. Policy Econ. 18, 38-45 (2012)

8. Meyfroidt, P. Glob. Food Secur. 16, 9-16 (2018).

9. Pretty, J. et al. Nat. Sustain. 1, 441-446 (2018).

10. Ricciardi, V., Mehrabi, Z., Wittman, H., James, D. \& Ramankutty, N. Nat. Sustain. 4, 652-657 (2021).

11. Havlík, P. et al. Proc. Natl Acad. Sci. USA 111, 3709-3714 (2014).

12. Nyström, M. et al. Nature 575, 98-108 (2019).

13. Powell, B. et al. Food Secur. 7, 535-554 (2015).

14. Isakson, S. R. J. Peasant Stud. 41, 749-775 (2014).

15. Jouffray, J. B., Crona, B., Wassénius, E., Bebbington, J. \& Scholtens, B. Sci Adv. 5, eaax3324 (2019).

16. Baker, L., Castilleja, G., De Groot Ruiz, A. \& Jones, A. Nat. Food 1, 765-767 (2020).

17. van de Sand, I. Ecol. Soc. 17, 11 (2012). 
18. Wood, S. A., Jina, A. S., Jain, M., Kristjanson, P. \& DeFries, R. S. Glob. Environ. Change 25, 163-172 (2014).

19. Impact Report (Near East Foundation, 2019).

20. Österblom, H. et al. PLoS ONE 10, e0127533 (2015).

21. CEOs of World's Leading Seafood Companies Commit to Time-Bound Goals for a Healthy Ocean (SeaBOS, 2020); https://go.nature.com/3Al6Q8S

22. Transparency to Transformation: A Chain Reaction. Global Supply Chain Report 2020 (CDP, 2021); https://go.nature.com/ $3 \mathrm{CrDszC}$

23. Figures at a Glance (UNHCR, accessed 21 February 2021); https://go.nature.com/3fHKpTE

24. de Coning, C. \& Krampe, F. Multilateral Cooperation in the Area of Climate-Related Security and Development Risks in Africa (NUPI, 2020).

25. Gibson, C. C., Andersson, K., Ostrom, E. \& Shivakumar, S. The Samaritan's Dilemma: The Political Economy of Development Aid (Oxford University Press Scholarship Online, 2005).

26. Zürcher, C. World Dev. 98, 506-522 (2017).

27. Loos, J. et al. Front. Ecol. Environ. 12, 356-361 (2014).

28. Garnett. T. et al. Sustainable Intensification in Agriculture:

Premises and Policies (American Association for the Advancement of Science, 2013).

29. Morgado, N. C. et al. Scaling Up Climate-Compatible Infrastructure (Organization for Economic Cooperation and Development, 2019)

30. Climate Resilience Principles: A Framework for Assessing Climate Resilience Investments (Climate Bonds Initiative, 2019).

31. Martín, C. S. et al. Articulating a Program for Resilience: The Landscape of Evidence, Actions, and Geographies (Urban Institute, 2020).
32. The World Bank Group Action Plan on Climate Change Adaptation and Resilience (World Bank, 2019).

33. Kariuki, L. N. in Agro-Food Chains and Networks for Development (eds Ruben, R. et al.) Ch. 3, 41-48 (Springer, 2006).

34. Goldberg, P. K. \& Pavcnik, N. The Effects of Trade Policy NBER Working Papers 21957 (National Bureau of Economic Research, Inc., 2016).

35. Smith, K. \& Lyons, K. in Food Systems Failure: The Global Food Crisis and the Future of Agriculture (eds Rosin, C. et al.) Ch. 12, 182-202 (Earthscan, 2012).

36. Kummu, M. et al. Glob. Food Secur. 24, 100360 (2020).

37. Gardner, T. A. et al. World Dev. 121, 163-177 (2019).

38. Grimard, A. et al. Supply Chain Transparency Network: State of Play (Global Canopy Programme \& Stockholm Environment Institute, 2017).

39. Committee on World Food Security Voluntary Guidelines on the Governance of Tenure of Land, Fisheries and Forests in the Context of National Food Security (FAO, 2012).

40. Paradza, G. et al. Land 9, 344 (2020).

41. Viña, C. S.-L. Beyond Title: How to Secure Land Tenure for Women (World Resources Institute, 2020)

42. Gordon, L. J. et al. Environ. Res. Lett. 12, 100201 (2017).

43. De Schutter, O. et al. Food Policy 96, 101849 (2020).

44. Gong, M., Gao, Y., Koh, L., Sutcliffe, C. \& Cullen, J. Int. J. Prod. Econ. 217, 88-96 (2019).

45. Norström, A. V. et al. Nat. Sustain. 9, 182-190 (2020).

46. Dentoni, D. et al. J. Bus. Ethics 150, 333-356 (2018).

47. Hiemstra, W. et al. Knowl. Manage. Dev. J. 9, 11-31 (2013).

48. EVI Indicators (UN DESA, accessed 23 March 2021);

https://go.nature.com/3Aem9QK

49. Hufschmidt, G. et al. Nat. Hazards 58, 621-643 (2011).
50. Fragile States Index (Fund for Peace, accessed 23 March 2021); https://go.nature.com/3fllEq2

51. FAOSTAT: Suite of Food Security Indicators (FAO, accessed 23 March 2021); https://go.nature.com/3xxxcCS

52. World Country Polygons - Very High Definition Shapefile (World Bank, accessed 20 November 2020); https://go.nature. com/3jCBaF5

Acknowledgements

We thank the Rockefeller Foundation for funding the Bellagio expert meeting convened by The Global Resilience Partnership (GRP) that set the foundation for this publication. C.Q. was funded by the project Guidance for Resilience in the Anthropocene: Investments for Development (GRAID) and the Swedish Marianne and Marcus Wallenberg Foundation (grant number 2017.0137). A.M.L. acknowledges funding from the CGIAR Research Program on Climate Change, Agriculture and Food Security (CCAFS), which is carried out with support from the CGIAR Trust Fund and through bilateral funding agreements. For details please visit https://ccafs.cgiar.org/donors.

Competing interests

The authors declare no competing interests.

Additional information

Peer review information Nature Food thanks Sonja Vermeulen and Erin Lentz for their contribution to the peer review of this work. 